\title{
Preterm Birth Changes Networks of Newborn Cortical Activity
}

\section{Tokariev, Anton}

2019-02

Tokariev , A , Stjerna , S , Lano , A , Metsäranta , M , Palva , J M \& Vanhatalo , S 2019 , ' Preterm Birth Changes Networks of Newborn Cortical Activity ' , Cerebral Cortex , vol. 29 , no. 2 , pp. 814-826 . https://doi.org/10.1093/cercor/bhy012

http://hdl.handle.net/10138/306400

https://doi.org/10.1093/cercor/bhy012

publishedVersion

Downloaded from Helda, University of Helsinki institutional repository.

This is an electronic reprint of the original article.

This reprint may differ from the original in pagination and typographic detail.

Please cite the original version. 
CORRIGENDUM

\section{Preterm Birth Changes Networks of Newborn Cortical Activity}

\section{Anton Tokariev ${ }^{1}$, Susanna Stjerna ${ }^{1}$, Aulikki Lano², Marjo Metsäranta ${ }^{3}$, J. Matias Palva ${ }^{4}$ and Sampsa Vanhatalo ${ }^{1}$}

${ }^{1}$ Department of Clinical Neurophysiology, University of Helsinki, 00029 HUS, Helsinki, Finland, ${ }^{2}$ Department of Child Neurology, Children's Hospital, University of Helsinki and HUH, Helsinki, Finland, ${ }^{3}$ Department of Neonatology, Children's Hospital, University of Helsinki and HUH, Helsinki, Finland and ${ }^{4}$ Neuroscience Center, Helsinki Institute of Life Science, University of Helsinki, Helsinki, Finland

Address correspondence to Anton Tokariev, BABA Center (www.babacenter.fi), Department of Clinical Neurophysiology, University of Helsinki, PO Box 280, 00029 HUS, Helsinki, Finland. Email: anton.tokariev@helsinki.fi

Cereb. Cortex (2018); 1-13. https://doi.org/10.1093/cercor/bhy012

Two authors were not included in the authorship list though they both had relevant contributions to the study performance and results.

Dr. Metsäranta is a neonatologist who was crucial in the patient recruitment and much of the clinical data collection.

Dr. Lano is a pediatric neurologist who was crucial in the neurological outcome studies.

The author names, affiliations, and contributions have been corrected in the article. 